\title{
Investigation of Biometric Sexual Differences on Humeral Articular Surfaces of New Zealand Rabbits via Photogrammetric Techniques
}

\author{
Abdullah Varlik ${ }^{1}$, Sema Ozkadif ${ }^{2, ~}$, Emrullah Eken ${ }^{3}$, Ibrahim Kalayci $^{1}$ \\ ${ }^{1}$ Department of Geodesy and Photogrammetry, Faculty of Architecture and Engineering, Necmettin Erbakan University, Konya, Turkey \\ ${ }^{2}$ Department of Nursing, School of Health, Batman University, Batman, Turkey \\ ${ }^{3}$ Department of Anatomy, Faculty of Veterinary Medicine, Selcuk University, Konya, Turkey \\ Email address: \\ avarlik@konya.edu.tr (A. Varlık), semaerten80@gmail.com (S. Ozkadif), eeken@selcuk.edu.tr (E. Eken), ikalaycı@konya.edu.tr (I. Kalayci)
}

\section{To cite this article:}

Abdullah Varlik, Sema Ozkadif, Emrullah Eken, Ibrahim Kalayci. Investigation of Biometric Sexual Differences on Humeral Articular Surfaces of New Zealand Rabbits via Photogrammetric Techniques. Animal and Veterinary Sciences. Vol. 3, No. 6, 2015 , pp. 153-157. doi: $10.11648 /$ j.avs.20150306.12

\begin{abstract}
The glenohumeral joint is a one of the joints most of which frequently dislocate. Moreover, in this joint various developmental disorders and pathological situations can be seen. The fact that it can perform the widest and the most diverse movements of our body makes the joint surfaces constituting the joint important. Therefore, in this study, surface areas of humeral head and glenoid cavity which form glenohumeral joint of 12 New Zealand rabbits of both sexes were measured, and their proportions to each other were determined on a three dimensional (3D) model obtained via photogrammetric methods. In conclusion, a statistically significant difference was identified between male and female rabbits regarding the joint surfaces constituting glenohumeral joint. Moreover, it was observed that the surface of humeral head was 3 times as large as the surface area of glenoid cavity. It has been suggested that the photogrammetric method that was used and the data that were obtained will shed light on forensic medicine applications and contribute to the information pool in the field of anatomy in veterinary medicine.
\end{abstract}

Keywords: Glenohumeral Joint, Photogrammetry, Rabbit, Surface Area, Three Dimensional Reconstruction

\section{Introduction}

Various cases such as developmental anomalies, fractures, dislocations, arthritis, different inflammatory and tumoral phenomena can be encountered in shoulder (glenohumeral) joint. Due to this critical significance of the area, morphometric studies in this regard gain importance at the stages of both diagnosis and treatment [1]. Before some simple surgical interventions, simulations of the shoulder joint can be used after making a 3D model of it [2]. The morphology of glenoid cavity and definition of various parameters were conducted on a reconstructed $3 \mathrm{D}$ model formed from computed tomography (CT) images [3]. 3D models are useful in shoulder arthroplasty especially in cases where pre-surgical planning is necessary [4].

Analysis and morphometry of human or animal bones, especially of their uneven surfaces is quite difficult. Various approaches exist to create 3D models of objects that have different shapes and characteristics. Among them are 3D coordinate measurement machines (CMM), laser scanning, photogrammetry and robotic methods. The most suitable method to create a 3D model in terms of both precision and cost, photogrammetry is regarded as a reliable method that deserves to be preferred in the examination and evaluation of bones [5]. Photogrammetric methods are quite advantageous in that they cost little, patients are not exposed to radiation and desired measurement values can be taken via the model formed [6]. Photogrammetry is a technology and branch of science where reliable information is obtained about objects and environment by recording, measuring and interpreting the photographic images formed by rays radiating from objects and the environment created by them. This method is used with high precision to identify measure and interpret the formal and characteristic properties of animate and inanimate beings. The greatest advantage of photogrammetry over the other methods of measurement is that measurements are taken on the photographic projection of the object rather than directly on the object. This property 
of indirect measurement allows photogrammetry to be used in different fields [7].

A photogrammetric system was formed to identify deformation that occurred in the vertebrae due to scoliosis and to monitor its progress, a 3D body model was created and measurements were taken on it [6].

Photogrammetric studies are also used in dentistry. In an orthodontic study, a 3D skull model created by making a photogrammetric evaluation of the images taken from 5 different angles and positions instead of X-ray images [8].

In addition, deformation analyses are also made using photogrammetric methods in veterinary surgery. Method was developed to measure deformation in horse hooves in different weight conditions and the hooves were evaluated photogrammetrically after their photographs were taken [9]. Photogrammetric technique was assessed for the characterization of equine foot volume changes associated with foot trimming [10].

Photogrammetric methods began to be used in veterinary anatomy studies, too. Different measurements were taken on a 3D model of the joint surfaces of the bones forming the shoulder joints of sheep, cats and rabbits created through photogrammetric methods, and differences among the species were revealed irrespective of gender [11]. Glenoid cavity which constitutes the shoulder joint, exhibits differences between the genders [12].

3D photogrammetry technique was developed to estimate morphometrics and body mass of Steller sea lions (Eumetopias jubatus) [13]. And also researches applied photogrammetric techniques to photographs taken by bird over 70 years ago, before the trackway was removed to digitally reconstruct the site as it was prior to excavation [14].

A review of literature that was conducted revealed that there were no studies explaining the morphometric properties in males and females of humeral head and glenoid cavity, which form the shoulder joint of the New Zealand rabbit. In order to meet this shortcoming in the relevant literature, measurements were taken on a 3D model created through photogrammetric methods, and a study was conducted to see the proportions of joint surfaces in terms of area and to determine whether the morphometric measurement values were statistically significant between the sexes.

\section{Materials and Methods}

The bones used in the study were obtained from New Zealand rabbits used in a project completed in early 2011 and supported by Coordination Office of Selcuk University Scientific Research Projects. Also it was accepted by the ethics committee of the Veterinary Faculty of Selçuk University on 24 June 2009 (decision number: 2009/056).

\subsection{Age and Weight}

In this study, a total of 12 New Zealand rabbits, 6 male and 6 female, aged 1-1.5 years and weighing between 3 and $3.5 \mathrm{~kg}$, were used.

\subsection{Dissection}

Rabbits were duly slaughtered and then the upper extremities were taken from the animals' bodies after dissecting them. The upper extremities, which were taken together with muscles and fat, were boiled in potassium hydroxide solution in order to rid them of these tissues. Scapula and humerus, which constitute glenohumeral joint, were thoroughly cleaned.

\subsection{Photogrammetric Assessment}

As a basis for photogrammetric assessment, objects need to be defined within a known coordinate system or coordinates need to be assigned to some points on the object during the taking of photographs (Fig.1). Since it is virtually impossible to measure the $3 \mathrm{D}$ coordinates of the points on the object via traditional methods, a new device was designed and coded targets were used for the control points.

Coded targets can be used to define a local coordinate system and model scale or to make accurate matching in picture alignment. The identification and matching of the coded targets in pictures is performed automatically by the software. The automatic marking of the targets saves time compared with the manual marking and alignment of the targets and produces more precise results than manual marking.

The measurements of the target points were also measured using this device. These points, which were measured and taken as known during the evaluation process, were measured two dimensional (2D) using a compass having a precision of $1 / 20 \mathrm{~mm}$.

Before photographs were taken, marks whose coordinates were known but had a size of $1.5 \mathrm{~mm}$ so as to yield clear images in the pictures taken were made on the bones surfaces randomly and in a way to be seen in all pictures.

The geometry of taking photographs has a significant place in the field of photogrammetric picture taking. In the study, a photograph scale was determined depending on the size of the object and taking into account the digital camera used, as well as a $\mathrm{B} / \mathrm{H}$ (base height) rate in accordance with this photograph scale and a shooting angle (plan). Pictures belonging to the object surfaces were taken using a 16-megapixel Sony DSC-W570 digital camera by raising the camera at an angle of about $30^{\circ}$ at an equal distance to the object, at a rate of $70 \%$ overlapping with one another and with a Base/Height ratio of 1/3 (Fig. 2)

Photoscan software was used in our study for photogrammetric evaluation. First, the internal routing elements of the camera used were calculated. The internal routing procedure requires reconstruction of the perspective rays of the setup in the camera in similar conditions. With this procedure, the focal length of the camera (f), coordinates of the projection center $\left(\mathrm{x}_{\mathrm{p}}, \mathrm{y}_{\mathrm{p}}\right)$, radial distortion $\left(\mathrm{k}_{1}, \mathrm{k}_{2}, \mathrm{k}_{3}\right)$ and tangential distortion $\left(\mathrm{p}_{1}, \mathrm{p}_{2}\right)$ values were calculated. The camera used in the study had been calibrated in previous studies and its calibration values were given in Table 1 .

The photogrammetric evaluation procedural steps of the 
Photoscan software consist of photograph alignment, formation of dense point clouds, formation of 3D model grid network, model tissue coating and location-referencing.

During the photograph alignment procedure, the software perceives the coded target points on the pictures automatically, performs automatic matching between the pictures and creates connection points by finding common points outside these coded target points. The position and routings of the camera during a photograph shooting are calculated by the help of these points. After this procedure, a point cloud model is created by making intensive point matching procedure between the stereo photograph couples (Fig. 3).

The georeferencing of the model is performed by conducting a 7-parameter (3- shifts, 3- rotation, 1 scale) transformation with at least three points whose real world coordinates are known. Since only the real dimensions of the model were needed in our study, transformation was implemented by scaling the model using the lengths between the coded target points. After the transformation, the differences between the real lengths of the control points and their calculated lengths were calculated by the software. Table 2 shows the results of a model belonging to the left humerus of a female New Zealand rabbit.

After conducting the georeferencing of the model, a digital surface model was formed by creating a 3D grid network from the dense point cloud (Fig. 4), and then the real 3D model of the object was obtained by coating (covering) the picture texture (Fig. 5). These procedures were performed for each bone and thus real 3D models were obtained for all the bones. The overall mean errors of the models that were obtained remained at about $0.00007 \mathrm{~m}(0.07 \mathrm{~mm})$. In other words, measurements can be taken on our models at a precision rate of $0.1 \mathrm{~mm}$.

The joint surface of the bones were selected manually on the real 3D models that were formed and thus their surface areas were measured (Fig. 6).

\subsection{Statistical Analysis}

The statistical analisis was performed by using SPSS 16.00 for Windows. The independent samples t-test was carried out and the mean values, standart deviations and P-values of surface area belonging to glenohumeral joint in the right and left side for males and females were calculated.

Nomina Anatomica Veterinaria [15] was used in terminology.

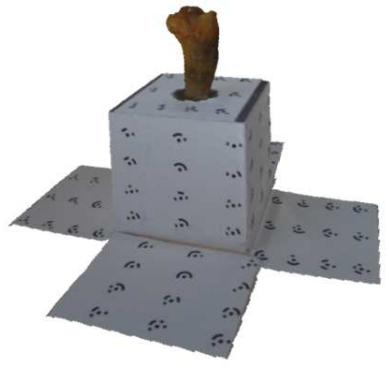

(a)

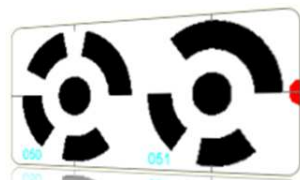

(b)
Figure 1. The device used to take photographs and coded target points (a, b).

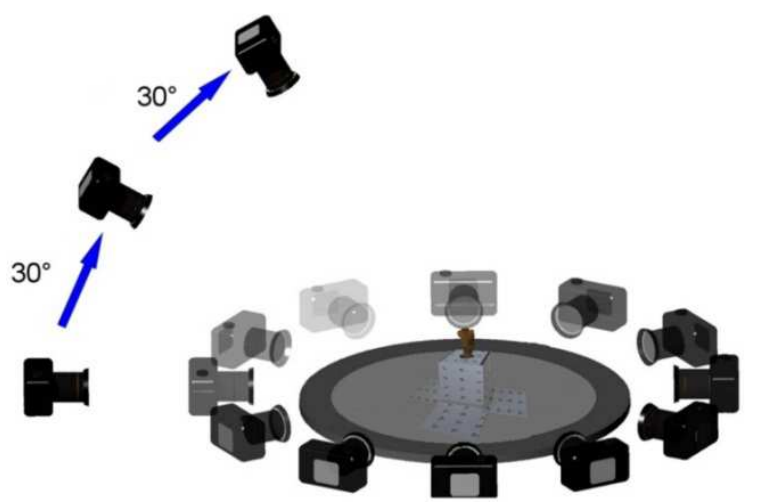

Figure 2. The simulated picture-taking procedure.

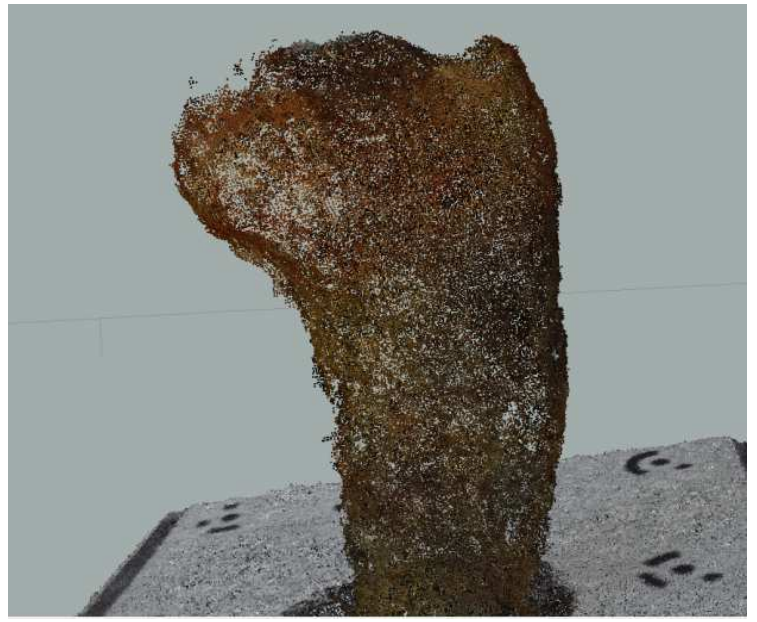

Figure 3. The point cloud model created as a result of intensive point matching.

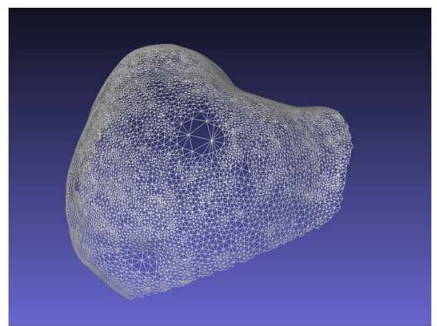

(a)

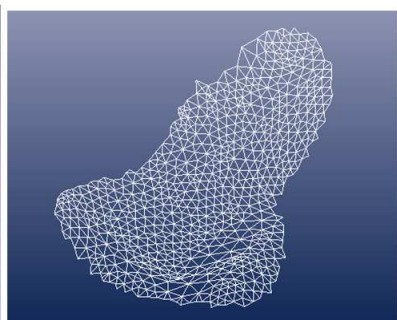

(b)
Figure 4. Creation of a digital surface model of a: humeral head and $b$ : glenoid cavity by forming a $3 D$ grid network.

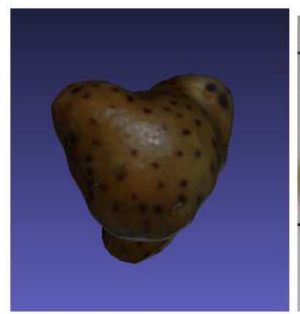

(a)

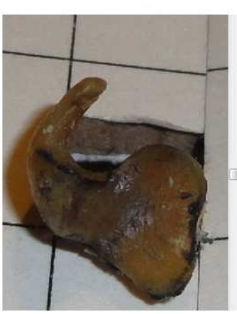

(b)

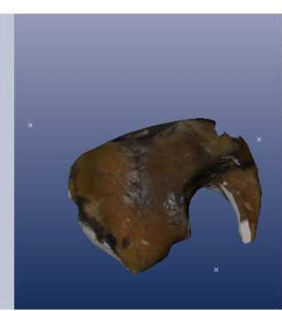

Figure 5. 3D modeling of the joint surface of a: humeral head and $b$ : glenoid cavity. 


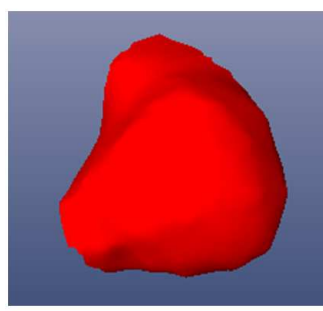

(a)

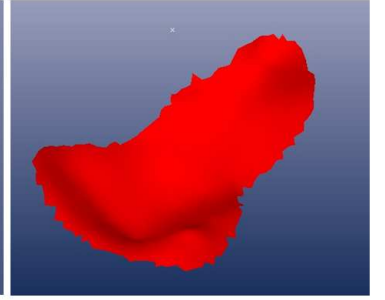

(b)
Figure 6. Calculation of surface areas of a: humeral head and b: glenoid cavity, which constitute glenohumeral joint.

Table 1. The calibration values of the camera (Sony DSC-W570) had been used in the study.

\begin{tabular}{ll}
\hline Focal Length- Shutter & $\mathbf{4 . 5 m m - 1 / 2 5 0 ( s n )}$ \\
\hline K1,k2,k3 & $4608 \times 3456$ \\
P1,p2 & $0,0524 \mathrm{~mm} / \mathrm{pix}$ \\
xo & $1.31527 \mathrm{pix}$ \\
yo & $0,104 \mathrm{~mm}$ \\
\hline
\end{tabular}

Table 2. The transformation results of a model belonging to the left humerus of a female New Zealand rabbit.

\begin{tabular}{lll}
\hline Points Id & Length $(\mathbf{m})$ & Error $(\mathbf{m})$ \\
\hline $1-3$ & 0.0092 & 0.000014 \\
$1-5$ & 0.0159 & 0.000017 \\
$3-7$ & 0.0159 & 0.000059 \\
$5-7$ & 0.0092 & 0.000054 \\
$5-9$ & 0.0159 & 0.000002 \\
$7-11$ & 0.0159 & 0.000018 \\
$9-11$ & 0.0092 & 0.000046 \\
$13-15$ & 0.0092 & 0.000032 \\
$11-15$ & 0.0159 & 0.000021 \\
$13-17$ & 0.0092 & 0.000079 \\
\hline
\end{tabular}

Table 3. Statistical results of biometric measurements belonging to glenohumeral joint obtained as a result of $3 D$ reconstruction (mean $\pm S D$ ).

\begin{tabular}{llll}
\hline & Photogrammetric & Right $(\mathbf{n}=6)$ & Left $(\mathbf{n}=6)$ \\
\hline \multirow{3}{*}{ Analysis } & Humeral head $\left(\mathrm{cm}^{2}\right)$ & $1.539 \pm 0.187$ & $1.547 \pm 0.182$ \\
& Glenoid cavity $\left(\mathrm{cm}^{2}\right)$ & $0.492 \pm 0.060$ & $0.498 \pm 0.060$ \\
& Humeral head / & $3.128 \pm 0.096$ & $3.108 \pm 0.076$ \\
& Glenoid cavity & $1.937 \pm 0.194$ & $1.972 \pm 0.207$ \\
\multirow{3}{*}{ Female } & Humeral head $\left(\mathrm{cm}^{2}\right)$ & $0.655 \pm 0.053$ & $0.651 \pm 0.058$ \\
& Glenoid cavity $\left(\mathrm{cm}^{2}\right)$ & $2.953 \pm 0.093$ & $3.026 \pm 0.103$ \\
\hline
\end{tabular}

$\mathrm{P}>0.05$; there was no statistically significant difference in the same line.

Table 4. Statistical comparison of biometric measurements belonging to left and right sides of glenohumeral joint obtained as a result of $3 D$ reconstruction (mean $\pm S D$ )

\begin{tabular}{llll}
\hline & $\begin{array}{l}\text { Photogrammetric } \\
\text { Analysis }\end{array}$ & Male $(\mathbf{n}=\mathbf{6})$ & Female $(\mathbf{n}=6)$ \\
\hline \multirow{4}{*}{ Right } & Humeral head $\left(\mathrm{cm}^{2}\right)$ & $1.539 \pm 0.187^{\mathrm{a}}$ & $1.937 \pm 0.194^{\mathrm{b}}$ \\
& Glenoid cavity $\left(\mathrm{cm}^{2}\right)$ & $0.492 \pm 0.060^{\mathrm{a}}$ & $0.655 \pm 0.053^{\mathrm{b}}$ \\
& Humeral head / & $3.128 \pm 0.096^{\mathrm{a}}$ & $2.953 \pm 0.093^{\mathrm{b}}$ \\
& Glenoid cavity & $1.547 \pm 0.182^{\mathrm{a}}$ & $1.972 \pm 0.207^{\mathrm{b}}$ \\
& Humeral head $\left(\mathrm{cm}^{2}\right)$ & $0.498 \pm 0.060^{\mathrm{a}}$ & $0.651 \pm 0.058^{\mathrm{b}}$ \\
& Glenoid cavity $\left(\mathrm{cm}^{2}\right)$ & $3.108 \pm 0.076$ & $3.026 \pm 0.103$ \\
\hline
\end{tabular}

${ }^{a, b}$ : Different letters in the same line are statistically significant $(\mathrm{P}<0.05)$.

\section{Results}

$3 \mathrm{D}$ coordinates and 3D digital terrain models of the required points in scapula and humerus, which form glenohumeral joint in the New Zealand rabbits, were obtained through the close-up picture photogrammetry method. Joint surface areas were calculated by the help of 3D digital terrain model, their proportions were identified and it was found that there was no statistically significant difference between the right and left sides in both males and females (Table 3.) that there was a statistical difference between the genders (Table 4).

According to Table 3, there were no statistically significant differences between the right and left sides in both sexes in the surface areas of humeral head and glenoid cavity and in the proportion of the surface area of humeral head to the surface area of glenoid cavity.

It was seen that in both sexes and in both sides, the surface area of humeral head was almost 3 times as large as the surface area of glenoid cavity.

According to Table 4, a difference at the level of $\mathrm{P}<0.05$ was found in the surface areas of male and female New Zealand rabbits constituting glenohumeral joint and their proportions to each other.

\section{Discussion}

Surface area measurements through photogrammetric methods of humeral head and glenoid cavity, which constitute glenohumeral joint in male and female New Zealand rabbits and their proportions to each other, were evaluated statistically. According to this, no statistically significant differences were observed between the joint surfaces in the right and left sides of both male and female rabbits whereas differences were found between the sexes. There weren't any statistically significant differences observed in glenoid cavity measurements of south Indian population [16] and Egyptian population [17] in the right and left sides as in New Zealand rabbit.

As a result of metamorphic measurements they conducted on male and female scapula, Taşer and Başaloğlu [1] found a statistical difference between the sexes. Moreover, it was shown through studies conducted that both the height and width measurements of glenoid cavity exhibited a statistically significant difference between the sexes [18]. Prescher and Klümpen [12] argued that glenoid cavity displayed sexual dimorphism but this alone was not sufficient in distinguishing the sexes and that other characteristic features belonging to the bone should be used to confirm this.

The shape of the glenoid cavity in New Zealand rabbits was look like to ellips and extended in one side, but in feral pigs (Sus scrofa) it was circular [19]. In Turkish adult population there were some variations of glenoid cavity according to the types of gleoid notch [20].

It was found in this study that the surface area of humeral head in New Zealand rabbits was about three times that of the surface area of glenoid cavity. Karabork [11] measured humeral head in rabbits as $161 \mathrm{~mm}^{2}$, and glenoid cavity as $64.7 \mathrm{~mm}^{2}$ which yielded a proportion of 2.5 times. In humans, 
on the other hand, humeral head was found to be $4 \mathrm{~cm}^{2}$, whereas glenoid cavity was measured to be $1.6 \mathrm{~cm}^{2}$ and the proportion was calculated to be 2.5 times [21].

In conclusion, according to the surface area measurements of the glenohumeral joint of New Zealand rabbits obtained through photogrammetric methods on 3D models, it was found that humeral head and glenoid cavity were important in sex assignment. It is believed that the photogrammetric method used and the data obtained could shed light on forensic medicine practices and contribute to the wealth of knowledge in the field of veterinary anatomy. In addition, it can be said that $3 \mathrm{D}$ data that were obtained in this study, which brought together the medical and photogrammetric disciplines/methods harmoniously, made a significant contribution to the medical field.

\section{References}

[1] Taşer FA, Başaloğlu H (2003) Morphometric dimensons of the scapula. Ege Journal of Medicine 42: 73-80.

[2] Atmani H, Merienne F, Fofi D, Troulloud P (2008) From medical data to simple virtual mock-up of scapulo-humeral joint. ELCVIA 7: 115-128.

[3] Moineau G, Levigne C, Boileau P, Young A, Walch G (2012) Three-dimensional measurement method of arthritic glenoid cavity morphology: Feasibility and reproducibility. Orthop Traumatol Surg Res 98: 139-145.

[4] Bryce CD, Pennypacker JL, Kulkarni N, Paul EM, Hollenbeak CS, Mosher TJ, Armstrong AD (2008) Validation of three-dimensional models of in situ scapulae. J Shoulder Elbow Surg 17: 825-832.

[5] Şeker DZ, Duran Z, Ege A (2002) Digital fotogrametrinin tıp alanında uygulanmasına bir örnek. 30. Yıl Sempozyumu, Konya, PP: 382-388.

[6] Chang YC (2008) A Photogrammetric system for 3D reconstruction of a scoliotic torso. Thesis of master program of biomedical engineering, university of Calgary, Alberta.

[7] Ege A, Şeker DZ, Tuncay İ, Duran Z (2002) Radius distal eklem yüzünün digital fotogrametrik yöntemle ölçme değerlendirmesi, VIII. Congress Book of the Turkish Society for Surgery of the Hand and Upper Extremity, Adana, 21/10: 128- 132 .

[8] Schewe H, Ifert F (2000) Soft tissue analysis and cast measurement in orthodontics using digital photogrammetry. ISPRS 33: 699-706.
[9] Jordan P, Willneff J, D’Apuzzo N, Weishaupt M (2001) Photogrammetric measurement of deformations of horse hoof horn capsules. Videometrics and Optical Methods for 3D Shape Measurement, Proceeding of SPIE, San Jose, California, 4309: 204-211.

[10] Labens R, Redding WR, Desai KK, Orde KV, Mansmann RA, Blikslager AT (2013) Validation of a photogrammetric technique for computing equine hoof volume. Vet J 197: 625-630.

[11] Karabork H (2009) Three- dimensional measurements of glenohumeral joint surfaces in sheep, cat and rabbit by photogrammetry. J Anim Vet Adv 8: 1248-1251.

[12] Prescher A, Klümpen TH (1995) Does the area of the glenoid cavity of the scapula show sexual dimorphism? J Anat 186: 223-226.

[13] Waite JN, Schrader WJ, Mellish JAE, Horning M (2007) Three- dimensional photogrammetry as a tool for estimating morphometrics and body mass of Steller sea lions (Eumetopias jubatus). Can J Fish Aquat Sci 64: 296-303.

[14] Falkingham PL, Bates KT, Farlow JO (2014) Historical photogrammetry: Bird's Paluxy river dinosaur chase sequence digitally reconstructed as it was prior to excavation 70 years ago. Plos One 9(4): 1-5.

[15] International Committee on Veterinary Gross Anatomical Nomenclature (2012) Nomina Anatomica Veterinaria. 5th ed., Hannover, Columbia, Ghent, Sapporo: World Association of Veterinary Anatomists.

[16] Mamatha T, Shakuntala R, Murlimanju BV, Kaltur SG, Mangala M, Kumar B (2011) Morphometry of glenoid cavity. OJHAS 10: $1-4$.

[17] El-Din WAN, Ali MHM (2015) A morphometric study of the patterns and variations of the acromion and glenoid cavity of the scapulae in Egyptian population. J Clin Diagn Res 9: 8-11.

[18] Churchill RS, Brems JJ, Kotschi H (2001) Glenoid size, inclination, and version: An anatomic study. J Shoulder Elbow Surg 10: 327-332.

[19] Karan M (2012) Macro-anatomical study of ossa membri thoracici in the feral pigs (Sus scrofa). Firat Univ Vet J Health Sci 26: 17-20.

[20] Coskun N, Karaali K, Cevikkol C, Demirel BM, Sindel M (2006) Anatomical basics and variations of the scapula in Turkish adults. Suudi Med J 27: 1320-1325.

[21] Sager M, Herten M, Ruchay S, Assheuer J, Kramer M, Jager M (2009) The anatomy of the glenoid labrum: A comparison between human and dog. Comp Med 59: 465-475. 